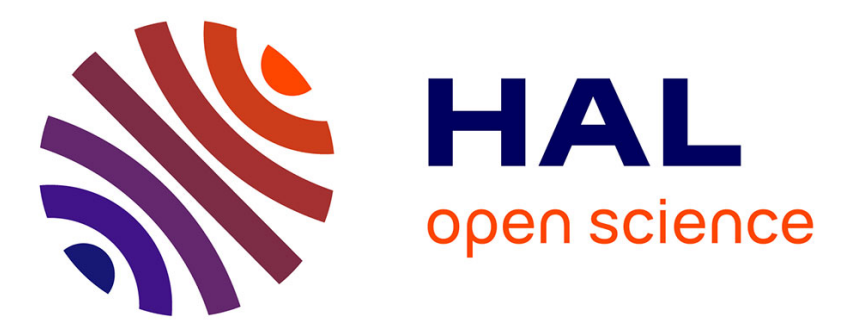

\title{
Measurement and Management of Supply Chain Performance: A Benchmarking Study
}

Siham Lakri, Yves Dallery

\section{To cite this version:}

Siham Lakri, Yves Dallery. Measurement and Management of Supply Chain Performance: A Benchmarking Study. IFIP International Conference on Advances in Production Management Systems (APMS), Sep 2014, Ajaccio, France. pp.433-440, 10.1007/978-3-662-44733-8_54 . hal-01387285

\section{HAL Id: hal-01387285 \\ https://hal.inria.fr/hal-01387285}

Submitted on 25 Oct 2016

HAL is a multi-disciplinary open access archive for the deposit and dissemination of scientific research documents, whether they are published or not. The documents may come from teaching and research institutions in France or abroad, or from public or private research centers.
L'archive ouverte pluridisciplinaire $\mathbf{H A L}$, est destinée au dépôt et à la diffusion de documents scientifiques de niveau recherche, publiés ou non, émanant des établissements d'enseignement et de recherche français ou étrangers, des laboratoires publics ou privés.

\section{(c)(1)}

Distributed under a Creative Commons Attribution| 4.0 International License 


\title{
Measurement and Management of Supply Chain Performance: a Benchmarking Study
}

\author{
Siham Lakri ${ }^{1}$ and Yves Dallery ${ }^{1}$ \\ ${ }^{1}$ Laboratoire Génie Industriel, Ecole Centrale Paris, Châtenay-Malabry, France \\ \{siham.lakri, yves.dallery\}@ecp.fr
}

\begin{abstract}
Over the past few decades, the role of Supply Chain (SC) has been evolving from cost centre to competitive advantage. That is why measurement and management of SC performance become particularly essential. However, such an undertaking is difficult due to the growing complexity of SC. As the literature review highlights it, there is a lack of survey dealing with measurement and management of SC performance, collecting data through interview process and especially addressed to large companies. This is the bias of the present paper. First, an overview of the benchmarking published on related topics is presented. Then, are detailed the selected sample, the methodology used to collect and analyse data and the preliminary results obtained. To finish, conclusions are presented followed by a discussion suggesting future research directions.
\end{abstract}

Keywords: Supply chain; Performance measurements; Performance management; Benchmarking study

\section{Introduction}

Over the past few decades, the role of supply chain (SC) has been evolving from cost centre to competitive advantage. The International survey "Global supply chain survey 2013", led by PwC group, show that companies acknowledging SC as a strategic asset generate a 30\% increase of profitability compared to the average (around 500 completed questionnaires from various industry sectors). Equally according to [1], supply chain management (SCM) is now recognised as one of the best means by which enterprises can make instant improvements to their business strategies and operations. Thus today's competition has shifted from inter-company level to intersupply chain level $[2,3,4,5]$.

Absolute growth lever of companies, SC formerly simple and linear, is nowadays considered as a complex system [6]. Although there are no generally accepted definitions of $\mathrm{SC}$, in coherence with the perimeter of this paper the following definition is taken on: "A supply chain consists of all parties involved, directly or indirectly, in fulfilling a customer request. The supply chain includes not only the manufacturers and suppliers, but also transporters, warehouses, retailers, and even customers themselves. Within each organisation, such as a manufacturer, the supply chain includes all 
functions involved in receiving and filling the customer request. These functions include, but are not limited to, new product development, marketing, operations, distribution, finance and customer service" [7]. Besides, today's environment is more dynamic [1] and SC have to satisfy regulatory requirements (societal pressures for example) and profitability requirements (financial, flexibility, competitiveness...). That is why during the last few decades focusing on factory level management has been replaced by firm level management of SC [8]. SC being considered as a key factor of corporate success [9], measurement and management of SC performance become essential. Nevertheless, such an undertaking is complex due to the transversal characteristic of these processes, involving numerous actors having to cooperate in order to reach given strategic objectives.

Therefore, the purpose of this paper is to review at what stage big size companies are about SC performance measurement and management concepts, highlight their current practices and the related main issues they have to cope with. To do so, a benchmarking study has been carried out, based on data collected through interview process from eleven multinational companies. The rest of the paper is organised as follows. The next section presents a literature review focusing on benchmarking survey dealing with SC performance measurement and management or related topics. Section 3 describes our empirical analysis, detailing the sample, the methodology used to collect and analyse data and preliminary results obtained. To finish Section 4 presents a discussion and conclusions.

\section{Overview of the Published Benchmarking Studies}

In this section, a literature review is established on benchmarking survey dealing with $\mathrm{SC}$ performance measurement and management concepts, or related topics.

Benchmarking is a well-known process aiming to improve performance by learning from the best performers in the class [10]. In this paper, the idea is to carry out such a comparative analysis, in order to observe the practices of several companies in the area of measurement and management of SC performance. This part aims to position the present benchmarking and the published benchmarking studies on a common framework described hereinafter. [11] introduced a matrix composed of two types of components. The first one answers the question: "What is benchmarked?" Three options are possible: Performance - how good performance is compared to others, Process - methods and processes used to improve organisational effectiveness and Strategic - changes in strategic directions and decisions. The second one answers the question "What to benchmark against?" It could be Internal - within the organisation, Competitor - within industry/sector, Functional - technology and techniques used, Generic - best practices from any sector or industry.

Only external benchmarking studies are reviewed in this paper, giving it is the type of the present benchmarking study detailed in section 3. Indeed, by definition, internal benchmarking studies deal with comparison of processes or operations within an organisation only. In this type of benchmarking, the acquisition of information is facili- 
tated. However, information obtained can be shortened and/or oriented, each one wanting to protect the interest of its department or its own.

In the literature review, two kind of benchmarking studies can be distinguished: 1Benchmarking launched in order to validate a framework built, 2- Benchmarking studies without framework to validate.

\subsection{Benchmarking Aiming to Validate a Framework Previously Developed}

The literature review shows that usually benchmarking process is used in order to validate a framework previously developed. For instance, [12] conceptualized, developed, and validated six dimensions of SCM practices (strategic supplier partnership, customer relationship, information sharing, information quality, internal lean practices, and postponement) using data collected from 196 manufacturing firms. [13] has empirically tested a framework identifying the causal links among SCM and information systems (IS) practices, SCM-IS related inhibiting factors and operational performance based on a sample of 203 manufacturing Small and Medium Enterprises (SMEs) within the greater metropolitan area of Istanbul in Turkey. Equally in manufacturing industry, [14] examined which dimensions are used by the largest Danish companies to measure supply chain performance measurement (SCPM) at operational, tactical and strategic level, how can these dimensions be classified, and how do these empirical results have implications for practice and selected SCPM-theories. The SCPM model they proposed has been theoretically developed and empirically validated. In the airline and airport field, [15] applied a two-step Data Envelopment Analysis (DEA) procedure to evaluate the operational performance of a sample of the Association of European Airlines, whereas [16] developed a holistic performance measurement system (PMS) for airport ramp service providers with a process-based perspective, and conducted a benchmarking study in several European hub airports. The authors followed the action research approach for defining the PMS, which associates weights to the measures in an Analytical Hierarchical Process, and grouped measures into the perspectives of the Balanced Scorecard.

\subsection{Benchmarking Studies without a Framework to Validate}

In the transport logistics context of Hong Kong, [17] conducted a benchmarking study considering efficiency (economic use of resources) and effectiveness (fulfilment of customer requirements) measures. The 134 responses obtained allowed to evaluate their perceived SC performance in transport logistics from both cost and service perspectives. On the other hand, without specific context, in order to justify that leadership behaviour measurement can and should be part of any performance measurement system, [18] gathered exploratory empirical data from 11 Finnish SMEs located in Western Finland. Another kind of topic, investigate what relevant forecasting variables should be considered to improve companies' performance. [19] analysed equally whether some forecasting variables can interact and influence performance with a synergistic effect by means of data collected by the Global Manufacturing Research Group from a sample of 343 manufacturing companies in 6 different countries. 
According to [20], while there is plenty of published literature that explains or espouses SCM, there is a relative lack of empirical studies examining SCM practices. [20] report the current status of SCM of manufacturing organisations in New Zealand. The outcomes suggest that although there is awareness of the SCM concept in New Zealand, the adoption of the newer concepts of SCM is not very advanced. [21] surveyed SCM practices in UK, collecting data from 288 industrial SMEs. The findings indicate a lack of effective adaptation from traditional adversarial relationships to the modern collaborative "e" - supply chain and also identifies issues businesses need to address to improve the performance of their supply chains. Similarly, [22] investigated practices and concerns of SCM in United States and concluded that all of significant SCM practices positively impact performance. Still about SCM practices but this time in Finland, [23] interviewed managers of six SC in order to analyse the change of SCM both in terms of operational practices and organisational capabilities. Some papers focus on metrics, as [24] which compared key performance indicators (KPIs) importance of 21 British companies or the collaborative survey [25] aiming at highlight KPI's use and consistency with companies' needs in France. While others are concentrated on process perspective, for instance [26] analysing the use of structured processes for the design of PMS in the UK (around 350 SMEs from a variety of industries) and [27] finding out about how SMEs in India apply Balanced Scorecard concept by the combination of three case studies and semi-structured interviews. The literature includes research works about strategy perspective as well. [28], using a representative sample of 156 organizations mostly from manufacturing, discuss SC strategies and structures in India whereas [29] conduct a survey that examines the success factors in developing and implementing SCM strategies for Hong Kong manufacturers. Finally, [30] compare performances of 68 European enterprises based on 5 KPIs from Supply Chain Operations Reference (SCOR) model, calculated using data from enterprise financial review.

To conclude, each of these studies are positioned in an adaptation of the matrix proposed by [11] in table1 presented below. Two main observations can be raised.

Table 1. Positioning of the studies reviewed on an adaptation of the [11] matrix

\begin{tabular}{|l|l|l|l|l|}
\hline & \multicolumn{4}{|c|}{ What to benchmark against? } \\
\hline \multirow{4}{*}{$\begin{array}{l}\text { What is } \\
\text { bench- } \\
\text { mark? }\end{array}$} & Performance & {$[15,16,17]$} & {$[19]$} & \multicolumn{1}{|c|}{ Generic } \\
\cline { 2 - 5 } & Process & {$[13]$} & {$[14],[20]$} & {$[12],[18],[21]$,} \\
& Strategy & & {$[28,29]$} & \\
\cline { 2 - 5 } & & & {$[23,24,25,26,27]$} \\
\hline
\end{tabular}

First, obviously, there is an empty square at the intersection between strategy and competitor because for a start it is quite difficult to convince long term partners of an organisation to adopt this approach thus it seems even more unattainable to obtain competitors approval for such a partnership. Similarly, it is empty at the intersection between strategy and generic, as it seems to have little interest to compare strategy of companies from various industries. Moreover, by definition, strategy cannot be imi- 
tated. Secondly, by contrast, the majority of the studies are placed at the intersection between process and generic as the present benchmarking study. However, there is a difference among these eight research works in the way to collect data. Six [12], [18], [21], [24,25,26] use questionnaires whereas [27] use semi-structured interviews then case studies and [23] lead interviews. Another distinction between the "processgeneric" benchmarking is the size of enterprises considered. Half of them concentrate only on SMEs ([18], [21], [26,27], two [12], [25] include SMEs as well as large companies and the two remaining $[23,24]$ focus on large companies.

As the literature review highlights it, there is a lack of survey collecting data through interview process and especially addressed to large companies and their related research in the area of SC performance. This is the bias of the present paper.

\section{Empirical Analysis}

The sample constructed referred to 11 multinational corporations which employ by far more than 5000 people. Three of them are Native American companies and the 8 others are French companies. The sectors represented are Fast-Moving Consumer Goods (FMCG), Household appliance, Automotive, Luxury, Distribution and Steel industry. The selected companies represent also different geographical locations in France as well as have SC management differently organised. The aim of our undertaking is mainly to highlight current practices in today's large companies, understand the principal trends and identify correlations regarding concepts of measurement and management of SC performance.

\subsection{Method to Collect Data and Data Analysis}

We met each company twice and led interviews of about two hours based on a previously developed questionnaire in order to guide the discussions. All interviews were held at the respective companies' office, which allows insuring an environment conducive to obtain information easily even the sensitive ones. Two or three persons per company have been interviewed. Respondents met are SC directors, with a national or worldwide perimeter and/or internal SC experts.

The first step to analyse data was to choose adequate comparison criteria. Further to interviews, we selected 11 coherent criteria from five key aspects: from SC organisation aspect (chain perimeter, process perimeter, group organisation), from measurement aspect (number of KPIs, shared KPIs), from management aspect (who define KPIs, who set KPIs' targets, who manage in the sense of reaching objectives, management tools), from performance aspect (type of performance measured), and the last criterion but not the least, is about company performance culture. Indeed, the enterprise culture is rarely taken into account in benchmarking studies while it is an important factor which influenced decision-making in general. As interviews were rich in information, it was primordial to find a way to make the data comparable. To do so, we built synthetic profile of each company. We will not go into further detail in this article. The following section shows the preliminary results obtained. 


\subsection{Preliminary Results}

First, there is a tendency to have many KPIs, more than 20 in $45 \%$ cases, which participate to the complexity of PMS. Clearly, the number and the choice of KPIs is still a problematic. The assessed performance remains predominantly economic, although we note ongoing project to evaluate environmental (36\%) and social (28\%) performance. Indeed, not only increasing societal pressures have an effect but also companies become more and more aware of the performance potential which could be resulting. Due to incomplete information about shared KPIs we feel inadequate to draw conclusions; however we can notice a difficulty to answer to that question which highlights a lack of visibility of what is shared with whom. The definition of KPIs for the most part occurred in centralized SC $(45 \%)$, which has the advantage to insure homogeneity of KPIs set of SC sites. Decision about KPIs' targets is also handled by central SC (36\%) in order to align overall objectives, i.e. strategic objectives, with SC sites objectives. On the other hand, local SC (64\%) managers are in charge of performance management through KPIs. In that, we detect the general wish to manage SC performance as closely as possible to the field. Regarding SC culture, of course influenced by corporate culture, the following key messages are conveyed: get unquestionable KPIs, get less KPIs more standardized, get a wide vision of performance, simplify PMS, simplify reporting process, share more widely, measure collaborators performance, be committed. Today's companies direct their efforts toward simplification, collaboration based on a common language and commitment. Results about tools used will not be presented in this article.

Three correlations can be raised. First, B-to-B companies are organized by global business unit; have a process perimeter extended in comparison with B-to-C companies and make measurement system reviewed by central SC. On the contrary, B-to-C companies are organized by geographical zone and revise measurement system locally. Finally, in the majority of cases ( $80 \%)$, KPIs' targets setting process and performance management process, in the sense of manage through KPIs, are owned by the same level (local/local or central/central). However, we note two exceptions from this observation. KPIs' targets are set by local SC and the reaching of targets is managed by central SC. We understand that people from SC sites have a better knowledge of the field to choose ambitious targets but above all attainable ones. The second exception describes the opposite case, KPIs' targets set by central SC and management to reach targets owned by local SC. We explain it by the fact local SC as we said previously have a better knowledge of the field and thus are the most likely to make the objectives achieved.

\section{Conclusions and discussion}

As the literature review highlights it, there is a lack of survey dealing with measurement and management of SC performance and especially which collect data through interview process and addressed to large companies. This is the bias of the present paper. We studied the current SC performance measurement and management practices of multinational corporations established in France. In this way, we cover a rea- 
sonable spectrum of firms from varied businesses. We highlighted, on one hand, measurement current tendencies as the density of measurement systems and type of performance measured in fact. On the other hand, we raised performance management current tendencies as KPIs definition, targets setting and performance management processes' decision levels in the SC. We also showed correlations illustrating B-to-B and B-to-C companies' profiles. We underlines that there is coherence between KPIs definition process and targets setting process being owned by the same decision level.

With this survey, we contribute with new findings that have implications for theory and offer to practitioners an up to date point of comparison. We proposed a cartography positioning published benchmarking studies, concerning several sectors, related to the SC performance issue according to the type of benchmarking. Moreover, through results, we delivered an overview of the state of progress of large companies regarding current key problematic.

Nevertheless, we present only a snap-shot view of the topic. First of all, a clear limitation to our study is the size of the sample. As we choose to proceed by interviews it would be difficult to drastically increase the number of companies to meet. Thus we can consider this study as an explorative one and not fully representative of the whole population. Besides, we collected data from SC directors and internal SC experts. It could be interesting to analyse the perceptions from other members of the SC or collaborators, such as suppliers or customers' points of view.

\section{References}

1. Kaihara, T.: Supply chain management with market economics. International Journal of Production Economics. 73, 5-14 (2001)

2. Burgess, K., Singh, P.J., Koroglu, R.: Supply chain management: a structured literature review and implications for future research. International Journal of Operations \& Production Management. 26, 703-729 (2006)

3. Lambert, D.M.: Supply chain management: processes, partnerships, performance. Supply Chain Management Institute, Sarasota, Fla. (2008)

4. Lummus, R.R., Vokurka, R.J.: Defining supply chain management: a historical perspective and practical guidelines. Industrial Management \& Data Systems. 99, 11-17 (1999)

5. Mentzer, J.T.: Fundamentals of Supply Chain Management: Twelve Drivers of Competitive Advantage. SAGE (2004)

6. Surana, A., Kumara, S., Greaves, M., Raghavan, U.N.: Supply-chain networks: a complex adaptive systems perspective. International Journal of Production Research. 43, 4235-4265 (2005)

7. Chopra, S., Meindl, P.: Supply chain management: strategy, planning, and operation. Pearson, Boston (2012)

8. Gunasekaran, A., Williams, H.J., McGaughey, R.E.: Performance measurement and costing system in new enterprise. Technovation. 25, 523-533 (2005)

9. Estampe, D., Lamouri, S., Paris, J.-L., Brahim-Djelloul, S.: A framework for analysing supply chain performance evaluation models. International Journal of Production Economics. (2010)

10. Fong, S.W., Cheng, E.W.L., Ho, D.C.K.: Benchmarking: a general reading for management practitioners. Management Decision. 36, 407-418 (1998) 
11. Bhutta, K.S., Huq, F.: Benchmarking - best practices: an integrated approach. Benchmarking: An International Journal. 6, 254-268 (1999)

12. Li, S., Rao, S.S., Ragu-Nathan, T.S., Ragu-Nathan, B.: Development and validation of a measurement instrument for studying supply chain management practices. Journal of Operations Management. 23, 618-641 (2005)

13. Bayraktar, E., Demirbag, M., Koh, S.C.L., Tatoglu, E., Zaim, H.: A causal analysis of the impact of information systems and supply chain management practices on operational performance: Evidence from manufacturing SMEs in Turkey. International Journal of Production Economics. 122, 133-149 (2009)

14. Algren, C., Kotzab, H.: State of the art of supply Chain performance measurement in Danish industrial companies. 23rd Annual NOFOMA Conference, Harstad, Norway (2011)

15. Barros, C.P., Peypoch, N.: An evaluation of European airlines' operational performance. International Journal of Production Economics. 122, 525-533 (2009)

16. Schmidberger, S., Bals, L., Hartmann, E., Jahns, C.: Ground handling services at European hub airports: Development of a performance measurement system for benchmarking. International Journal of Production Economics. 117, 104-116 (2009)

17. Lai, K.-H., Ngai, E.W.T., Cheng, T.C.E.: An empirical study of supply chain performance in transport logistics. International Journal of Production Economics. 87, 321-331 (2004)

18. Kulmala, H.I., Ahoniemi, L., Nissinen, V.: Performance through measuring leader's profiles: An empirical study. International Journal of Production Economics. 122, 385-394 (2009)

19. Danese, P., Kalchschmidt, M.: The impact of forecasting on companies' performance: Analysis in a multivariate setting. International Journal of Production Economics. 133, 458-469 (2011).

20. Basnet, C., Corner, J., Wisner, J., Tan, K.-C.: Benchmarking supply chain management practice in New Zealand. Supply Chain Management: An International Journal. 8, 57-64 (2003)

21. Quayle, M.: A study of supply chain management practice in UK industrial SMEs. Supply Chain Management: An International Journal. 8, 79-86 (2003)

22. Tan, K.C.: Supply Chain Management: Practices, Concerns, and Performance Issues. Journal of Supply Chain Management. 38, 42-53 (2002)

23. Kemppainen, K., Vepsäläinen, A.P.J.: Trends in industrial supply chains and networks. International Journal of Physical Distribution \& Logistics Management. 33, 701-719 (2003)

24. Gunasekaran, A., Patel, C., McGaughey, R.E.: A framework for supply chain performance measurement. International Journal of Production Economics. 87, 333-347 (2004)

25. Kurt Salmon, Generix Group, Aslog, Agora du Supply Chain Management: Supply chain Quels KPIs pour les managers en 2014-2015? (2013)

26. Neely, A., Mills, J., Platts, K., Gregory, M., Richards, H.: Performance measurement system design: Should process based approaches be adopted? International Journal of Production Economics. 46-47, 423-431 (1996)

27. Bhagwat, R., Sharma, M.K.: Performance measurement of supply chain management: A balanced scorecard approach. Computers \& Industrial Engineering. 53, 43-62 (2007)

28. Sahay, B.S., Mohan, R.: Supply chain management practices in Indian industry. International Journal of Physical Distribution \& Logistics Management. 33, 582-606 (2003)

29. Chin, K.-S., Tummala, V.M.R., Leung, J.P.F., Tang, X.: A study on supply chain management practices: The Hong Kong manufacturing perspective. International Journal of Physical Distribution \& Logistics Management. 34, 505-524 (2004)

30. Estampe, D.: Benchmark de la supply chain. Techniques de l'Ingénieur. (2011) 